Cahiers $d u$ MONDE RUSSE

\section{Cahiers du monde russe}

Russie - Empire russe - Union soviétique et États indépendants

$50 / 2-3 \mid 2009$

L'Europe orientale, 1650-1730. Crises, conflits et renouveau

\title{
BesatzerSilke SATJUKOW
}

, Göttingen : Vandenhoeck \& Ruprecht, 2008, 405 p., 6 ill., 10 tabl.

\section{Jörg Echternkamp}

\section{(2) OpenEdition}

\section{Journals}

Édition électronique

URL : https://journals.openedition.org/monderusse/9788

DOI : 10.4000/monderusse.9788

ISSN : $1777-5388$

Éditeur

Éditions de l'EHESS

Édition imprimée

Date de publication : 15 septembre 2009

ISBN : 978-2-7132-2260-3

ISSN : $1252-6576$

Référence électronique

Jörg Echternkamp, «BesatzerSilke SATJUKOW », Cahiers du monde russe [En ligne], 50/2-3 | 2009, mis en ligne le 14 janvier 2013, consulté le 02 septembre 2022. URL : http://journals.openedition.org/ monderusse/9788; DOI : https://doi.org/10.4000/monderusse.9788

Ce document a été généré automatiquement le 2 septembre 2022.

Tous droits réservés 


\title{
BesatzerSilke SATJUKOW
}

, Göttingen : Vandenhoeck \& Ruprecht, 2008, 405 p., 6 ill., 10 tabl.

\author{
Jörg Echternkamp
}

\section{Silke SATJUKOW, Besatzer, «Die Russen» in Deutschland 1945-1994, Göttingen : Vandenhoeck \& Ruprecht, 2008, 405 p., 6 ill., 10 tabl.}

1 Armée libératrice et non d'occupation: officiellement, la glorieuse Armée rouge avait libéré l'Allemagne du fascisme et du capitalisme. Grâce à cette présentation des faits, l'héroïsme soviétique devint la pièce maitresse du mythe antifasciste servant à légitimer l'existence de la RDA. Plus d'un demi-million de soldats soviétiques vécurent en Allemagne de l'Est entre 1945 et 1994. Lorsque la présence du Groupe Ouest des troupes soviétiques en Allemagne prit fin comme prévu le 9 septembre 1994 et que les derniers soldats soviétiques quittèrent Berlin en direction de la Russie, leur retrait n'eut pas l'éclat des cérémonies triomphales qui avaient été réservées aux troupes américaines, britanniques et françaises. L'amitié germano- soviétique, vantée par la propagande, se heurtait à la volonté des commandants soviétiques d'éviter des relations étroites entre leurs hommes et la population.

Quelle évolution ont connue les relations complexes entre les soldats soviétiques et la population est-allemande dans ce champ de tensions qui a duré un demi-siècle ? C'est sur cette question directrice que Silke Satjukow se penche dans son Habilitationsschrift (HDR, Université d'Iéna). Partant de l'histoire politique, administrative et économique de l'occupation soviétique, l'auteur ajoute une dimension d'histoire culturelle en étudiant le contexte de l'occupation, d'une part, et les interactions ou interdépendances entre soldats soviétiques et population est-allemande, sur les plans institutionnel et personnel, de l'autre. En ce qui concerne la méthode, Satjukow associe les études macro- et microhistoriques en dégageant les structures générales (juridiques, politiques, économiques et militaires) pour leur donner corps à l'aide de trois cas concrets. D'où des « descriptions étoffées » de la vie quotidienne sous l'occupation dans une grande ville (Dresde), dans une ville moyenne de province (Weimar) et dans l'agglomération de Nohra, avoisinant 
un camp de manœuvre. L'éventail des sujets étudiés va donc du droit international jusqu'au match de foot.

3 Le plan peut étonner : il commence par la fin, à savoir par une chronique politique du retrait des troupes en 1994 (ch. I). Après avoir expliqué sa démarche, Satjukow ajoute trois autres parties dans l'ordre chronologique des phases qu'il distingue. Couvrant la période qui va de la fin de la guerre jusqu'à 1961, le deuxième chapitre est consacré à « l'arrivée et [à] l'installation des forces d'occupation ». Le troisième décrit la " période d'occupation » qui va de la construction du mur de Berlin jusqu'au retrait des troupes en 1994. La gamme des sujets traités dans cette partie (qui est de loin la plus vaste de l'ouvrage) va de la vie quotidienne dans les casernes jusqu'aux problèmes écologiques et aux relations amoureuses, en couvrant au passage désertion, décès, réseaux économiques et poursuites pénales... Dans le quatrième et dernier chapitre, l'auteur tente d'élaborer une interprétation théorique de ces relations entre l'armée soviétique et la population est-allemande, qui ont donc duré près de cinquante ans. Partant du principe d'une délimitation réciproque, Satjukow distingue quatre lignes de fracture correspondant à des phases de rapprochement et d'éloignement, qu'elle associe aux expériences liées aux différentes générations. Ainsi, en 1947, les troupes sont tenues à l'écart de la population allemande; en juin 1953, la politique de "construction du socialisme» et de démonstration de la puissance militaire soviétique (accord de stationnement de 1957), poursuivie par le SED, parti socialiste unifié de l'ex-RDA, aboutit à de nouveaux compromis; en 1961, la construction du mur, après la fin de l'installation des armées d'occupation, pose les jalons permettant « de roder pendant des décennies des formes de compromis praticables "; enfin, à la fin des années 1970, la guerre en Afghanistan, la glasnost et la perestroïka marquent le début d'une dernière phase qui remet en cause ces routines (p. 316). Finalement, il ne reste presque plus rien du mythe de la libération et de l'amitié entre libérateurs et libérés.

4 L'auteur achève son analyse en estimant que les cinquante années d'occupation sont caractérisées par «une oscillation permanente entre distance et proximité, rapprochement et éloignement »(p. 329). Elle emploie une notion empruntée à la psychosociologie en relevant «un phénomène d'accordéon». À ses yeux, le rapprochement après la fin de la guerre aurait fait naître un désir de distance aussi bien chez les occupants que chez les occupés - la transgression de certaines limites paraissant indésirable ou incontrôlable, notamment en ce qui concerne les craintes et les blessures liées à l'histoire. Si la routine du quotidien favorise le rapprochement, ces ressentiments produisent l'effet inverse, c'est-à-dire un désir d'éloignement. Le tournant historique dans les rapports « chiastiques » entre citoyens soviétiques et est-allemands est expliqué par «la nécessité mentale d'alterner sans cesse entre distance et proximité » (p. 330): " chiastiques ", parce que l'occupant, vainqueur (de la guerre) et perdant (au quotidien) fait face à l'occupé vaincu (à la fin de la guerre) tout en étant gagnant (au quotidien). Selon l'auteur, cette "situation croisée » (p. 316) aurait marqué la façon dont la population, toutes générations confondues, a géré les traumatismes collectifs. Pour se débarrasser de leurs sentiments de honte et de culpabilité, les Allemands de l'Est transmettent l'image endommagée qu'ils ont d'eux-mêmes à l'identité de leurs enfants qui se voient attribuer de surcroît l'effort de réparation de guerre. Ainsi la génération suivante est-elle divisée en deux: soit elle contribue à la reconstruction, soit elle méprise les Russes en général dans l'intention de refouler le passé (p. 315). 
Pour conclure, l'auteur pose la question - intéressante - de savoir à quel point la vie en commun, pendant un demi-siècle, des Allemands de l'Est et de l'un des plus grands groupes de victimes de la Seconde Guerre mondiale a changé, au-delà de la rhétorique officielle, les représentations que les uns se faisaient des autres. Les résultats des quelques projets d'histoire orale (Lutz Niethammer) laissent entrevoir que les Allemands de l'Est avaient en effet une image plus nuancée des soldats soviétiques que les citoyens de la République fédérale où les vieux clichés sur l'ennemi avaient encore cours. Les Allemands de l'Est reconnaissaient que l'URSS avait fait de grands sacrifices. Très peu des personnes interrogées en 1990 déclarent avoir été gênées par la présence des soldats stationnés en RDA, même s'il n'y avait pas d'amitié véritable. Reste à savoir si les amis étrangers, ayant fait des expériences similaires avec le système socialiste, ont finalement contribué à l'émergence d'un sentiment collectif ou de solidarité est-allemand (p. 333).

L'auteur fournit une présentation riche des faits, qui se lit assez facilement, sur un sujet peu étudié jusqu'à présent. On retiendra surtout les passages dans lesquels la vie quotidienne parfois étrange sous l'occupation est décrite à l'aide d'exemples choisis. Par contre, elle aurait pu éclairer davantage la dimension histoire militaire du sujet, les occupants étant en fait des soldats. On aurait donc aimé en savoir plus sur les rapports entre l'Armée rouge et l'armée populaire nationale. Le plan original de l'ouvrage vient compliquer la lecture. En plaçant délibérément la fin au début, l'auteur court un risque particulièrement élevé en termes de raccourcissement téléologique. Si l'interprétation psychologisante propose une explication, elle est cependant en grande partie sans rapport avec la présentation proprement dite et semble un peu forcée. Celui qui s'attend à une analyse générale portant sur l'ensemble de l'Allemagne de l'Est restera sur sa faim : ce n'est qu'à la page 27 que le lecteur apprend que l'étude est limitée à Dresde, Weimar et Nohra. Si l'auteur a choisi une approche axée sur l'histoire culturelle, on déplore cependant l'absence d'une analyse des mythes et des médias liés à la présence des forces armées. Mais celle-ci fait l'objet d'un deuxième volume du même auteur qui vient d'être publié : Befreiung? Die Ostdeutschen und 1945 (Leipzig 2009). 